\title{
Geen pauliana? Gelukkig hebben we de onrechtmatige daad nog...
}

\author{
Commentaar bij HR 10 oktober 2014, ECLI:NL:HR:2014:2930, JOR 2014/297 \\ (Kameleon Beheer IV/Bisscheroux q.q.)
}

\author{
Mr.J.H.L. Beckers*
}

\begin{abstract}
1 De feiten
Per 1 juli 2006 bestond de vastgoedportefeuille van Hahnraths uit een vijftal panden. Ingegeven door financiële problemen vond in 2006 en 2007 een aantal rechtshandelingen plaats. In het kort:
\end{abstract}

\section{- Panden Xen $Y$}

Op 31 juli 2006 werd een tweetal panden (hierna: X en $\mathrm{Y})$ gezamenlijk verkocht, via een zekere Zipp, aan makelaar Sijstermans. Nadien kwam pand X, via terugkoop door Hahnraths, terecht bij Pommé (18 juli 2007), die het niet veel later doorverkocht aan Global Red BV (29 augustus 2007). Pand Y kwam uiteindelijk (1 oktober 2007), wederom via Hahnraths, terecht bij Kameleon, waarvan Pommé enig bestuurder was.

Pand X had in 2005 een WOZ-waarde van $€ 224$.500. In de opeenvolgende transacties ging het van de hand voor $€ 100.000$ (Hahnraths-Zipp en Zipp-Sijstermans), $€ 100.500$ (Sijstermans-Hahnraths en HahnrathsPommé) en € 235.000 (Pommé-Global Red). In de koopakten waarbij Hahnraths partij was, werd telkens een economische waarde genoemd van $€ 128.000$. In de koopakte Sijstermans-Hahnraths werd vermeld dat aan Hahnraths tevens waren verkocht de bij het pand behorende roerende zaken voor een koopprijs van $€ 12.500$. Hahnraths verklaarde later als getuige dat hij naast de officiële koopsom nog een bedrag van $€ 25.000$ 'zwart' had ontvangen.

Pand Y was voor de WOZ getaxeerd op $€ 365.000$. In de opeenvolgende transacties werd respectievelijk $€ 150.000$ (Hahnraths-Zipp en Zipp-Sijstermans) en $€ 159.500$ (Sijstermans-Hahnraths en Hahnraths-Kameleon) betaald. In de koopakten zelf werd telkens een economische waarde genoemd van $€ 197.000$ en ook hier vermeldde de koopakte Sijstermans-Hahnraths een bedrag van $€ 12.500$ aan roerende zaken. Kameleon had pand Y nog niet verkocht op het moment dat het hof arrest wees.

\footnotetext{
Mr. J.H.L. Beckers is professional support lawyer bij NautaDutilh te Amsterdam en als fellow verbonden aan het Van der Heijden Instituut van de Radboud Universiteit Nijmegen.
}

- Z-panden

Op 20 maart 2007 had Hahnraths een tweetal andere panden (hierna: de Z-panden) bezwaard met een recht van hypotheek ten behoeve van Krimat NV wegens een schuld aan deze, tot terugbetaling waarvan Hahnraths en Wimmer (echtelieden) zich hadden verbonden in hun hoedanigheid van vennoten van de vof 'cafetaria Hahnraths'. De vof werd gedreven vanuit een van genoemde panden.

Op 1 april 2008 zijn de vof 'cafetaria Hahnraths', Hahnraths en haar vennoten Hahnraths en Wimmer bij vonnis van de Rechtbank Maastricht op eigen aangifte in staat van faillissement verklaard.

\section{Oordeel in feitelijke instanties}

De curator vorderde in eerste aanleg een verklaring voor recht dat een aantal rechtshandelingen rechtsgeldig vernietigd was, waaronder: (1) het bij akte(n) van 20 maart 2007 gevestigde hypotheekrecht (betreffende de Z-panden), (2) het bij akte(n) van 18 juli 2007 en 1 oktober 2007 gevestigde recht van eigendom (pand X en Y), en (3) de hoofdelijke verbondenheid tot de schulden waarvoor de op 20 maart 2007 gevestigde hypotheek is verleend (opnieuw betreffende de Z-panden). Bovendien vorderde de curator een verklaring voor recht dat Krimat, Kameleon en Pommé jegens crediteuren van gefailleerden, althans jegens Hahnraths, onrechtmatig hebben gehandeld en dientengevolge schadeplichtig zijn. Ten slotte vorderde hij hoofdelijke veroordeling van Krimat, Kameleon en Pommé tot teruggave van hetgeen zij uit de vernietigde rechtshandelingen hebben ontvangen, alsmede tot betaling van schadevergoeding, alles met veroordeling in de proceskosten.

Het kernverwijt van de curator is dat alle betrokken partijen met voormelde transacties beoogden (de overwaarde van) de panden te onttrekken aan het verhaal van de crediteuren van Hahnraths. De vernietigingsvordering stoelt op artikel 42 en 47 van de Faillissementswet $(\mathrm{Fw})$ en de onrechtmatige-daa- 
dactie van artikel 6:162 van het Burgerlijk Wetboek (BW). ${ }^{1}$ De curator betoogde verder dat Pommé en Kameleon zich schuldig hebben gemaakt aan medeplegen, althans uitlokken van bedrieglijke bankbreuk (art. 341 van het Wetboek van Strafrecht, Sr).

De rechtbank heeft samengevat voor recht verklaard dat de hypotheekrechten ter zake van de Z-panden rechtsgeldig zijn vernietigd en dat de curator het hypotheekrecht van Krimat op die registergoederen niet behoefde te eerbiedigen. ${ }^{2}$ De overige vorderingen werden afgewezen.

In hoger beroep had de curator meer succes. Het hof stelt voorop dat Hahnraths bij het voorlopig getuigenverhoor verklaarde:

1. dat hij pand X en Y noodgedwongen beneden de waarde aan Sijstermans had verkocht, dat Pommé hem zou helpen die verkoop terug te draaien en dat Pommé daarna die panden voor een hogere prijs zou verkopen;

2. dat Pommé en hij ieder de helft van de winst zouden krijgen; en

3. dat Pommé had voorgesteld om de Z-panden in een door Hahnraths op te richten BV onder te brengen en die panden met een tweede hypotheek te bezwaren, zodat de panden geen overwaarde meer zouden hebben en derden niet meer tot executieverkoop zouden kunnen overgaan.

Volgens het hof ondersteunt deze verklaring de door de curator gestelde intentie van Pommé en Hahnraths 'om alles in het werk te stellen' om gelden en/of voor verhaal vatbare zaken uit handen van crediteuren van Hahnraths te houden. Die intentie vindt verder steun in het daadwerkelijk gerealiseerd zijn van een tweede hypotheek op de Z-panden en in het feit dat in de akten van levering van de panden $\mathrm{X}$ en $\mathrm{Y}$ aan respectievelijk Pommé en Kameleon een lagere koopprijs is vermeld dan Hahnraths daarvoor zowel volgens zijn eigen verklaring bij het voorlopig getuigenverhoor als volgens Pommé in diens verklaring bij het voorlopig getuigenverhoor daadwerkelijk zou of heeft ontvangen. Dat de verkoop van de panden meer zou opleveren dan alleen de in de leveringsakten vermelde koopprijzen acht het hof geloofwaardig, aangezien niet valt in te zien welk belang Hahnraths zou hebben bij een ongedaan maken van de verkopen aan Sijstermans indien hij de panden vervolgens voor dezelfde prijs aan Pommé beoogde te verkopen (r.o. 4.2.5).

Voor vernietiging op grond van de pauliana ziet het hof geen grond. Uitgaand van het feit dat in de akten van verkoop en levering van de panden $\mathrm{X}$ en $\mathrm{Y}$ niet de prijzen zijn vermeld die Hahnraths daadwerkelijk zou ontvangen, zijn de verkopen van die panden niet aan te merken als paulianeus vanwege de tussen Hahnraths en respectievelijk Pommé en Kameleon over-

1. Zie de door de A-G geciteerde overwegingen van de rechtbank, concl. nr. 1.3.2.

2. Nu hiertegen niet was gegriefd (door Krimat NV (gedaagde in eerste aanleg)), stond dit vast in hoger beroep en cassatie. eengekomen koopprijzen. Het hof acht het enkele feit dat Hahnraths ook bij de tussen Pommé en hem over de verkopen gemaakte afspraken niet het volle pond voor de panden verkreeg, (eveneens) onvoldoende om de desbetreffende verkopen als zodanig paulianeus te achten. Daarbij neemt het hof in aanmerking dat Hahnraths zelf niet over de financiële middelen beschikte om de eerdere verkopen aan Sijstermans terug te draaien en de transacties met Pommé en Kameleon voor hem (dus) een middel waren om alsnog voor die panden een hogere opbrengst te realiseren dan hij daaruit bij de verkoop aan Sijstermans had gerealiseerd. De enkele omstandigheid dat Pommé c.s. aan die transacties hebben meegewerkt en/of die transacties hebben bewerkstelligd vanwege een voor hen daarin gelegen voordeel, makkt niet dat zij door de verkoop van de panden zichzelf boven andere crediteuren van Hahnraths hebben willen bevoordelen (r.o. 4.2.6). Het standpunt van de curator dat de panden zonder terugkoop door Hahnraths voor verhaal door diens crediteuren beschikbaar zouden zijn geweest, verwerpt het hof. Daartoe overweegt het dat de verkoop van de panden aan Pommé c.s. niet los moet worden gezien van de terugkoop van die panden van Sijstermans; een terugkoop kon zonder wederverkoop niet worden gerealiseerd. De curator slaagt er niet in hard te maken dat hij zonder terugkoop door Hahnraths de panden had kunnen opeisen wegens bedrog bij de verkoop aan Sijstermans dan wel hij daarzonder van laatstgenoemde schadevergoeding had kunnen vorderen. Het hof deelt in zoverre het oordeel van de rechtbank dat niet is gebleken dat de crediteuren van Hahnraths door het samenstel van de transacties zelf zijn benadeeld (r.o. 4.2.7).

Het hof oordeelt wel dat aan Pommé c.s. ter zake de verkoop van de panden $\mathrm{X}$ en $\mathrm{Y}$ onrechtmatig handelen valt te verwijten in het feit dat zij die verkopen zodanig hebben gerealiseerd dat het positieve resultaat van die verkopen buiten bereik van de crediteuren van de vof en Hahnraths en Wimmer werd gehouden (r.o. 4.2.8). Daaraan legt het ten grondslag de eerdere vaststellingen omtrent Hahnraths' verklaringen over het doel van de constructie met Pommé c.s. (r.o. 4.2.5).

Ten slotte, hoewel de curator schadevergoeding nader op te maken bij staat vorderde, kan naar het oordeel van het hof de schade aanstonds worden vastgesteld door middel van begroting ex aequo et bono op EUR 80.000 (r.o. 4.3.1-4.3.2). Een gedeelte daarvan ter grootte van EUR 50.000 - waarvoor Pommé wordt veroordeeld - dient te worden beschouwd als schade in het kader van de verkoop van pand X. Het resterende gedeelte van EUR 30.000 - waarvoor Pommé hoofdelijk met Kameleon wordt veroordeeld - betrof pand Y (hoewel (nog) geen doorverkoop had plaatsgevonden).

\section{Oordeel Hoge Raad}

Tegen het vonnis van het hof komen Pommé en Kameleon vergeefs op in cassatie; de Hoge Raad vernietigt wel, maar enkel voor wat betreft de door het hof buiten beschouwing 
gelaten kostenveroordeling in eerste aanleg, waarover in het incidentele cassatieberoep werd geklaagd door de curator.

Het eerste onderdeel betoogt dat het hof, gelet op HR 16 juni 2000, NJ 2000/578 m.nt. Van Schilfgaarde (Van Dooren/ ABN Amro I), heeft miskend dat feitelijke gronden die geen paulianeus handelen opleveren evenmin een onrechtmatige daad kunnen opleveren. In dat kader is verder aangevoerd dat het hof buiten het partijdebat is getreden met zijn oordeel dat sprake is van bijzondere omstandigheden die buiten de desbetreffende rechtshandelingen zijn gelegen, alsmede dat dat oordeel onvoldoende is gemotiveerd. De Hoge Raad gaat daar niet in mee. In de eerste plaats overweegt hij dat het oordeel van het hof over onrechtmatig handelen van Pommé en Kameleon betrekking heeft op andere feiten en omstandigheden dan zijn oordeel over de pauliana. Het 'onrechtmatigheidsoordeel' in r.o. 4.2.8 ziet immers niet op (het doel van) de overeenkomsten zelf, maar op de omstandigheid dat bij de uitvoering ervan (onder meer bij de vastlegging van de overeengekomen koopprijzen in akten) een deel van de koopprijzen aan het zicht van de crediteuren is onttrokken. Het hof is ook niet buiten de grenzen van de rechtsstrijd getreden. Ook indien de curator ter onderbouwing van zijn vordering wegens onrechtmatige daad heeft volstaan met een verwijzing naar de feiten die hij ten grondslag heeft gelegd aan zijn vordering op grond van de pauliana, behoefde dat het hof niet ervan te weerhouden om een deel van die feiten ten grondslag te leggen aan zijn onrechtmatigheidsoordeel. Bij dat oordeel, dat zag op de transacties met pand $\mathrm{X}$ en $\mathrm{Y}$, mocht het hof overigens ook de gang van zaken rond de Z-panden betrekken, zonder daarmee buiten de rechtsstrijd te treden.

Het tweede onderdeel klaagt vanuit verschillende invalshoeken over de door het hof bij wege van schatting vastgestelde schadevergoeding. $\mathrm{Na}$ een overzicht te hebben gegeven van de stand van het recht, concludeert de Hoge Raad dat partijen ermee rekening moeten houden dat de rechter, met inachtneming van een aantal voorbehouden, direct kan overgaan tot vaststelling van de schadevergoeding, ook indien schadevergoeding op te maken bij staat is gevorderd. Anders dan het onderdeel betoogt, brengt dus in zo'n geval de enkele omstandigheid dat partijen geen specifiek op de omvang van de schade gericht debat hebben gevoerd nog niet mee dat de rechter hen in de gelegenheid moet stellen nadere gegevens over de omvang van de schade over te leggen. Uitgaande van de aan de stukken ontleende concrete schadefactoren en bijbehorende bedragen die het hof in r.o. 4.3.2 vermeldt, bieden de klachten volgens de Hoge Raad geen aanknopingspunt voor het oordeel dat het hof in dit geval de hem toekomende beoordelingsvrijheid heeft overschreden. Dit wordt niet anders doordat het hof vervolgens de schade bij wege van schatting heeft begroot, nu de schattingen hun grondslag vinden in concrete gegevens ontleend aan de stukken van het geding. Het hof was niet gehouden te motiveren waarom het niet kon komen tot een (meer) concrete vaststelling van de schade.
Het derde onderdeel betoogt dat Pommé pas aansprakelijk is indien hem persoonlijk een ernstig verwijt kan worden gemaakt, hetgeen het hof niet had betrokken bij zijn oordeel dat Pommé met Kameleon hoofdelijk zal worden veroordeeld tot vergoeding van de schade die het met betrekking tot pand $\mathrm{Y}$ heeft begroot. $\mathrm{Na}$ aanhaling van de beide 5 september-arresten (RCI/Kastrop en Hezemans/Van der Meer) overweegt de Hoge Raad dat het onderdeel terecht is voorgesteld. Niettemin kan het onderdeel niet tot cassatie leiden. De door het hof in r.o. 4.2.5 genoemde omstandigheden waarop het zijn onrechtmatigheidsoordeel baseert, komen erop neer dat Pommé niet alleen in privé (pand $\mathrm{X}$ ), maar ook in de hoedanigheid van bestuurder van Kameleon (pand Y) doelbewust met Hahnraths heeft samengespannen om een gedeelte van de overeengekomen koopprijzen aan het zicht van crediteuren van Hahnraths te onttrekken. Dit laat geen andere conclusie toe dan dat Pommé persoonlijk een ernstig verwijt kan worden gemaakt van de door Kameleon gepleegde onrechtmatige daad.

\section{Commentaar}

1. Deze zaak is om verschillende redenen interessant, maar vooral omdat duidelijk wordt dat in 'onttrekking aan verhaal'-situaties het stranden van een pauliana-vordering niet meteen betekent dat ook de kansen op een succesvolle onrechtmatige-daadactie zijn verkeken. Het arrest is kort besproken in JIN 2015/33 door El Houzi.

2. In appel ging het om de vraag of Pommé en 'zijn' vennootschap Kameleon zich schuldig hebben gemaakt aan benadeling van de crediteuren in de faillissementen van de vof 'cafetaria Hahnraths', Hahnraths zelf en diens echtgenoot. De curator meende van wel en beriep zich op de pauliana (art. 42 en $47 \mathrm{Fw}$ ) en onrechtmatige daad (art. 6:162 BW).

3. Ik veroorloof mij nog een enkele opmerking over de feiten; die zijn in deze casus belangrijk voor zowel de inhoudelijke beoordeling van pauliana en onrechtmatigheid (nr. 4 e.v.) als de schadevaststelling (nr. 17). Ondanks - of misschien wel dankzij - de voorlopige getuigenverhoren van Hahnraths, Wimmer en Pommé wordt niet volledig duidelijk wat nu precies beoogd werd met deze transacties en hoe zij in werkelijkheid werden afgewikkeld. Vaststaat dat Hahnraths een reeks vastgoedtransacties heeft verricht, waarbij op papier een koopsom werd betaald die beneden de werkelijke economische waarde lag. Onduidelijk is of Hahnraths enig bedrag zwart heeft ontvangen, zoals hij verklaarde (zie Hoge Raad, r.o. 3.1 onder vii), en of Hahnraths daadwerkelijk heeft gedeeld in de winst die Pommé (gedeeltelijk) realiseerde bij het doorverkopen van pand $\mathrm{X}$, zoals Pommé verklaarde; Hahnraths en Wimmer spraken dat tegen.

4. Het hof zag onvoldoende aanknopingspunten voor de pauliana. De curator richtte daartegen om hem moverende redenen geen klachten. Desondanks ziet de Hoge Raad reden het oordeel van het hof op dit punt samen te vatten (r.o. 4.1.2): 
'a) Hahnraths heeft overwaarde van de panden moeten prijsgeven bij de (...) transacties met Zip/Sijstermans. De terugkoop door Hahnraths van de panden met directe doorverkoop aan Pommé c.s. bood voor Hahnraths de mogelijkheid om een gedeelte van die overwaarde terug te krijgen, hetgeen hij zonder tussenkomst van Pommé c.s. niet kon bereiken. Dit wijst niet op samenspanning om crediteuren te benadelen.

b) Het voor verhaal vatbare vermogen van Hahnraths was reeds verminderd door de (niet aantastbare) transacties met Zip/Sijstermans. De overeenkomsten met Pommé en Kameleon hebben als zodanig de crediteuren niet benadeeld, aangezien deze overeenkomsten niet los kunnen worden gezien van de terugkoop van de panden van Sijstermans, die alleen door tussenkomst van derden Pommé en Kameleon - kon worden gerealiseerd.'

5. Uit de overwegingen van het hof rijst het beeld dat het zijn bedenkingen had bij de gang van zaken, maar uiteindelijk niet anders kon dan de vordering afwijzen. Verkoop van een zaak beneden de marktwaarde is een klassiek pauliana-geval, maar voor vernietiging van de benadelende rechtshandeling moet aan alle vereisten zijn voldaan. De angel zat hier in de niet-aantastbaarheid van de eerste benadelende transactie (Hahnraths - Zipp/Sijstermans), daardoor werd het benadelende karakter aan de latere transacties ontnomen. Kennelijk heeft de curator niet de stelling betrokken dat die eerste transactie benadelend was en uit dien hoofde vernietigbaar, afzonderlijk dan wel als 'samenstel van rechtshandelingen' (het hof spreekt, in een iets ander verband, van een 'samenstel van transacties', r.o. 4.2.8). Mogelijk had de beslissing dan anders geluid. Ik wijs er volledigheidshalve op dat in de samenstel-route een aantal valkuilen bestaat waarover in de literatuur wordt getwist. ${ }^{3}$

6. In gevallen als deze, waarin over de onzuivere intenties van betrokkenen geen discussie bestaat (vergelijk hof, r.o. 4.2.5), kan mogelijk ook een beroep worden gedaan op nietigheid wegens strijd met de goede zeden. Aanknopingspunten daarvoor biedt HR 19 december 2014, NJ 2015/290 m.nt. Tjong Tjin Tai, r.o. 3.3.2:

'Voor nietigheid van een rechtshandeling wegens strijd met de goede zeden op de grond dat deze strekt tot benadeling van schuldeisers, is niet vereist dat ten tijde van het aangaan van de rechtshandeling vaststaat of aannemelijk is dat schuldeisers als gevolg van de rechtshandeling daadwerkelijk (zullen) worden benadeeld. De nietigheid vindt reeds haar grond in de door het hof vastgestelde onzedelijke strekking van de rechtshandeling, en (anders dan het geval is bij de rechtsgevolgen van paulianeus of onrechtmatig handelen) niet in de nadelige gevolgen van de rechtshandeling voor anderen.'

Een bijkomend voordeel van de nietigheidssanctie is dat zich hier geen samenloop lijkt voor te doen met een even- tuele parallelle onrechtmatige-daadvordering (waarover uitgebreid hierna). ${ }^{4}$

7. In cassatie gaat het niet om het oordeel van het hof over de pauliana zelf, maar wordt een beroep gedaan op HR 16 juni 2000, NJ 2000/578 m.nt. Van Schilfgaarde (Van Dooren/ABN Amro I), waaruit volgt dat een rechtshandeling die niet vernietigbaar is op grond van artikel 42 en $47 \mathrm{Fw}$ slechts onder bijzondere omstandigheden als onrechtmatig kan worden aangemerkt. Meer in het bijzonder stelt het desbetreffende onderdeel dat feitelijke gronden die geen paulianeus handelen opleveren evenmin een onrechtmatige daad kunnen opleveren. Daarmee zal zijn gedoeld op de overweging uit eerdergenoemd arrest: '(...) dat na verwijzing opnieuw zal moeten worden onderzocht of de vordering van de curator op grond van de derde grondslag [pauliana; JB] moet worden toegewezen, en dat derhalve na verwijzing ook de vierde grondslag [onrechtmatige daad; JB] zo nodig opnieuw aan de orde kan komen, voorzover deze is gebaseerd op hetzelfde feitencomplex als de derde grondslag.'

8. Het onderdeel vangt bot. Volgens de Hoge Raad had het oordeel van het hof over onrechtmatig handelen van Pommé en Kameleon wel degelijk betrekking op andere feiten en omstandigheden dan zijn oordeel over de pauliana. De overeenkomsten zelf achtte het immers geoorloofd (lees: niet paulianeus), de onrechtmatigheid zat in de uitvoering ervan. Ik vind dit een wat gekunsteld onderscheid, maar dat komt misschien omdat ik moeite heb met het volgen van de pauliana-overwegingen (zie hiervoor nr. 4 e.v.). Verderop overweegt de Hoge Raad dan nog dat ook indien de curator ter onderbouwing van zijn onrechtmatige-daadvordering heeft volstaan met een verwijzing naar de feiten die hij ten grondslag heeft gelegd aan zijn vordering op grond van de pauliana, dat het hof niet ervan behoefde te weerhouden 'om een deel van die feiten ten grondslag te leggen aan zijn oordeel in r.o. 4.2.8'. Weliswaar respondeert de Hoge Raad hier op klachten betreffende de grenzen van de rechtsstrijd en innerlijke tegenstrijdigheid, maar toch is niet geheel duidelijk hoe zich dit verhoudt tot de overweging dat hier niet sprake was van 'hetzelfde feitencomplex'. Uit het voorgaande lijkt in ieder geval te kunnen worden geconcludeerd dat de Hoge Raad geen zware eisen stelt; zolang aan de onrechtmatige-daadvordering ook andere feiten en omstandigheden ten grondslag liggen, vormt de niet-vernietigbaarheid op grond van de pauliana geen beletsel. Hierbij speelt een rol dat, zoals de Hoge Raad benadrukt, de appelrechter veel vrijheid heeft bij de uitleg van de stellingen van partijen.

9. Hiermee lijkt vast te staan dat voor 'bijzondere omstandigheden' in Van Dooren/ABN Amro I moet worden gelezen 'bijkomende omstandigheden', dat wil zeggen

4. Zie ook noot 2 van Tjong Tjin Tai bij HR 19 december 2014, NJ $2015 / 290$.
3. Zie R.J. van der Weijden, De faillissementspauliana (diss. Nijmegen) (Serie O\&R, deel 75), Deventer: Kluwer 2012, p. 36-42. 


\section{Maandblad}

Ondernemingsrecht

omstandigheden buiten de rechtshandeling sec. ${ }^{5}$ In de literatuur is ook wel gesuggereerd dat het om 'bijzonder krasse' omstandigheden moet gaan, waarbij als voorbeelden worden genoemd selectieve betalingen aan groepsmaatschappijen en 'ongeoorloofde pressie'. ${ }^{6}$ Gelet op het door de Hoge Raad gemaakte onderscheid tussen de overeenkomst zelf (de rechtshandeling sec dus) en de uitvoering daarvan, lijkt het er sterk op dat de Hoge Raad hier voor de eerste benadering kiest. Dat het hier ook om een kras geval ging, doet daaraan niet af.

10. Dan de onrechtmatige-daadvordering zelf, voor zover gericht tot Pommé in de hoedanigheid van enig bestuurder van Kameleon. In cassatie wordt geklaagd dat het hof ten onrechte heeft nagelaten te toetsen of er sprake was van ernstige verwijtbaarheid. Volgens de Hoge Raad is die klacht op zichzelf terecht; niettemin kan het onderdeel niet tot cassatie leiden. De door het hof genoemde omstandigheden komen erop neer dat Pommé niet alleen persoonlijk (pand X), maar ook in de hoedanigheid van bestuurder van Kameleon (pand Y) doelbewust met Hahnraths heeft samengespannen om een gedeelte van de overeengekomen koopprijzen aan het zicht van crediteuren van Hahnraths te onttrekken. Volgens de Hoge Raad 'laat [dit] geen andere conclusie toe dan dat Pommé persoonlijk een ernstig verwijt kan worden gemaakt van de door Kameleon gepleegde onrechtmatige daad' (r.o. 4.5.4).

11. Het is niet de eerste keer dat de Hoge Raad zich bereid toont een hofbeslissing te 'redden' waarin ten onrechte het ernstig-verwijtcriterium buiten toepassing is gelaten. ${ }^{7}$ In de meeste gevallen ging het er niet zozeer om - zoals Assink het omschrijft - of het hof expliciet verwees naar een ernstig-verwijtmaatstaf, als wel of de overwegingen van het hof ten minste kenbaar aansloten op hetgeen toepassing van die maatstaf (met inachtneming van de omstandigheden van het geval) vergt. Wat dat betreft lijkt deze uitspraak wel in het rijtje te passen.

12. Deze uitspraak past ook in een ander rijtje (dat het hiervoor bedoelde grotendeels overlapt): in verschillende uitspraken beantwoordde het gewrakkte handelen aan zowel de gewone als de ernstig-verwijtmaatstaf. In zoverre ligt deze uitspraak in het verlengde van HR 23 november 2012, NJ 2013/302 m.nt. Van Schilfgaarde, JOR 2013/40 m.nt. Van Andel \& Rutten (Van de Riet/Hoffmann), HR 23 mei 2014, NJ 2014/325 m.nt. Van Schilfgaarde, JOR 2014/229 m.nt. Van Bekkum (X/Maas q.q.) en HR 5 september 2014, NJ 2015/21 m.nt. Van Schilfgaarde, JOR 2014/296 m.nt. Kroeze (Hezemans/Van der Meer). Dat betekent uiteraard niet dat de ernstig-verwijt-

5. Aldus R.J. de Weijs, Groene Serie Faillissementswet, Deventer: Kluwer (losbl.), art. 42, aant. 13 en A-G Wissink voor onderhavige zaak, nr. 3.4.3 en 3.5 .

6. Zie NJ-annotator Van Schilfgaarde onder Van Dooren-ABN Amro I.

7. Zie voor een opsomming B.F. Assink, De factor 'wetenschap van benadeling' in te onderscheiden vormen van bestuurdersaansprakelijkheid, in: Eenheid en verscheidenheid (congresbundel) (nog te verschijnen). norm zinloos is, wel dat die norm voornamelijk een functie heeft bij minder evident laakbaar gedrag.

13. Deze casus is in zoverre uniek dat Pommé de verweten gedraging had verricht zowel persoonlijk (pand $\mathrm{X}$ ) als in de hoedanigheid van bestuurder van Kameleon (pand Y). In zo'n geval lijkt het mij schier ondenkbaar dat beide transacties aan een andere maatstaf zouden zijn getoetst, enkel omdat de ene in hoedanigheid is verricht. Inmiddels is wel duidelijk dat bestuurdersaansprakelijkheid niet zo binair is als sommigen aannamen na Van de Riet/Hoffmann. Dat volgens Hezemans/Van der Meer 'steeds' de ernstig-verwijtmaatstaf moet worden aangelegd indien het gaat om bestuurdersaansprakelijkheid, laat onverlet dat in gevallen waarin het bestuurderschap een bijkomstigheid is, de indringendheid waarmee aan die maatstaf wordt getoetst dat ook zal zijn. Uiteraard zijn er nog meer omstandigheden die daartoe kunnen nopen.

14. Bijzonder aan dit geval is verder dat Pommé als bestuurder aansprakelijk werd geoordeeld voor benadeling van crediteuren van een derde, dus niet zijn eigen crediteuren of die van de BV. Het gaat hier dus niet om de 'klassieke' bestuurdersaansprakelijkheid jegens crediteuren van de aangesprokene zelf of van entiteiten binnen zijn invloedssfeer. Voor de inhoudelijke analyse maakt het feit dat het om derden-crediteuren gaat op zichzelf geen verschil, dat blijkt ook uit onderhavige uitspraak. Hierin volgt de onrechtmatige daad de pauliana, waarin het voor degene die met de schuldenaar een paulianeuze rechtshandeling aangaat per definitie om benadeling van derden-crediteuren gaat. Slechts onder bijzondere omstandigheden lijkt daarbij een rol te kunnen spelen dat het niet om zijn eigen crediteuren gaat. ${ }^{8}$

15. Is met het 'onttrekken aan het zicht van crediteuren' nu een geheel nieuwe aansprakelijkheidsgrond gecreëerd? Dat denk ik niet, uiteindelijk gaat het toch nog steeds om onttrekking aan of frustratie van verhaal (Ontvanger/ Roelofsen, categorie II); op aan het zicht onttrokken vermogensbestanddelen kunnen crediteuren zich niet verhalen. Dat blijkt ook bij de schadebegroting door het hof, waarbij het enkel spreekt van de 'buiten bereik van de crediteuren gehouden verkoopopbrengst' (r.o. 4.3.2). Wel kan deze nieuwe subcategorie aanleiding geven tot toepassingsvragen waarvoor het bestaande kader geen antwoorden biedt. De meest voor de hand liggende vraag is uiteraard wanneer sprake is van onttrekking aan het zicht, hetgeen vooral in minder krasse gevallen dan de onderhavige een lastige kan zijn.

16. In eerste instantie voerde de curator nog aan dat Pommé en Kameleon zich schuldig hebben gemaakt aan medeplegen, althans uitlokken van bedrieglijke bankbreuk (art. $341 \mathrm{Sr}$ ) doordat de panden aan de boedel zijn onttrokken en/of beneden de werkelijke waarde zijn vervreemd. Dit betoog, dat door de rechtbank werd verworpen (r.o. 4.21), lijkt niet te zijn gehandhaafd in hoger

8. Zie bijv. F.P. van Koppen, Actio Pauliana en onrechtmatige daadvordering (diss. Tilburg), Deventer: Kluwer 1998, p. 295. 


\section{Maandblad}

beroep. Het gaat hier hooguit om een steunargument; deze zaak speelde zich immers niet af voor de strafrechter. Overigens biedt het strafrecht de mogelijkheid om een schadevergoedingsmaatregel op te leggen. ${ }^{?}$

17. De kwestie van de schadevaststelling bij wijze van begroting ex aequo et bono laat ik grotendeels buiten beschouwing. De feitenrechter heeft daarbij veel vrijheid en de overwegingen van de Hoge Raad zijn goed te volgen. Het is natuurlijk wel frappant dat het hof dit uitgerekend doet in een zaak als deze, waarin niet alleen de omvang van de schade zelf onderwerp van discussie was, maar ook of er wel sprake was van benadeling/schade met de hiervoor besproken gevolgen voor de toewijsbaarheid van de pauliana-vordering. Wat ongetwijfeld geholpen zal hebben voor de Hoge Raad is dat dat laatste in cassatie niet aan de orde was gesteld.

18. Het faillissement van Hahnraths - en dat van Wimmer volgde uit het faillissement van de vof; in totaal drie faillissementen dus. De onrechtmatige-daadvordering van de curator lijkt hier voornamelijk te zijn ingesteld namens de crediteuren van Hahnraths (zie echter ook r.o. 4.2.8). Dat is ook niet verwonderlijk omdat daar het zwaartepunt van benadeling en schade lag; niet gebleken is dat er een huwelijksgemeenschap bestond tussen Hahnraths en Wimmer en dat het vastgoed daarin viel. Kan de curator ook optreden namens de gezamenlijke crediteuren in de faillissementen van de vof en Wimmer? Ik zou denken van wel, zij het alleen voor eerstgenoemde groep. In het geval van het faillissement van een vof en de vennoten, zoals in casu, zal vrijwel steeds ook sprake zijn van benadeling van gezamenlijkheid van de vennootschapscrediteuren, juist vanwege het feit dat zij zich kunnen verhalen op het vennootschapsvermogen én de privévermogens van de vennoten. Dat daarin een rangorde zit, in die zin dat vennootschapscrediteuren voor privécrediteuren gaan, is niet van belang; voor een onderzoek omtrent de individuele positie van elk van de betrokken crediteuren is geen plaats. ${ }^{10}$

19. Voor toekomstige gevallen geldt het nieuwe uitgangspunt dat het faillissement van de vof niet noodzakelijk het faillissement van de vennoten met zich brengt. ${ }^{11}$ In de onderhavige casus zou dat weinig verschil hebben gemaakt, behalve dat de vennoten waarschijnlijk zouden hebben gekozen voor de afslag van de schuldsaneringsregeling, direct bij aangifte van de vof dan wel naderhand op de voet van artikel $15 \mathrm{~b} \mathrm{Fw}$. Bij die tweede route is overigens maar de vraag of, zoals de Hoge Raad aanneemt, de rechtbank, hangende de daarvoor gestelde termijn, inderdaad ex artikel 3a lid 2 Fw de faillietverklaring van de vof

9. Zie bijv. HR 22 april 2014, NJ 2015/184 m.nt. Van Mierlo. Zie ook B. Wessels, Gevolgen van faillietverklaring (2), Deventer: Kluwer 2013 , nr. 3029-3029a.

10. Zie HR 23 december 1994, NJ 1996/628 (Notarissen/THB), r.o. 4.3.2. Een verdergaande stelplicht wordt aangenomen door Hof 's-Hertogenbosch 9 september 2014, JOR 2014/343 m.nt. Kerstens en Vroom.

11. Zie HR 6 februari 2015, NJ 2015/181 m.nt. Kortmann en Faber (X) Bepro). zal schorsen; in de verschillende rechtbanken werd daar in het verleden verschillend mee omgegaan. ${ }^{12}$
12. Zie M.H.F. van Vugt \& R.J. Verschoof, Twee geloven op één kussen samenloopproblematiek faillissement en schuldsaneringsregeling bij de vof, FIP 2014/134, p. 116-118. 